\title{
Results of cataract surgery in the very elderly population
}

This article was published in the following Dove Press journal:

Clinical Interventions in Aging

6 August 2013

Number of times this article has been viewed

\author{
Katarzyna Michalska- \\ Małecka' \\ Mariusz Nowak ${ }^{2}$ \\ Piotr Gościniewicz' \\ Jacek Karpe ${ }^{3}$ \\ Ludmiła Słowińska- \\ Łożyńska ${ }^{4}$ \\ Agnieszka Łypaczewska' \\ Dorota Romaniuk' \\ 'Department of Ophthalmology, \\ University Hospital No 5, Medical \\ University of Silesia, Katowice, \\ ${ }^{2}$ Pathophysiology Division, \\ Department of Pathophysiology and \\ Endocrinology, Medical University \\ of Silesia, Zabrze, ${ }^{3}$ Department of \\ Anesthesiology and Intensive Therapy, \\ Medical University of Silesia, Zabrze, \\ ${ }^{4}$ Department of Biophysics, Faculty \\ of Medicine in Zabrze, Medical \\ University of Silesia, Katowice, Silesia, \\ Poland
}

Correspondence: Katarzyna MichalskaMałecka

Sybiraków Street 18, 44-203 Rybnik,

Silesia, Poland

$\mathrm{Tel}+48600064150$

Fax +48 324329100

Email kasia@marat.com.pl
Aim: The aim of our study was to retrospectively evaluate the effectiveness and safety of cataract surgery and intraocular lens implantation (IOL) for patients aged 90 years or older, whom we define as "very elderly."

Methods: The study involved a total number of 122 patients (122 eyes) with senile cataracts. The mean age of patients was $91.2 \pm 2.3$ years (range 90-100 years old). Phacoemulsification (phaco) was done on 113 of 122 eyes, and 9 of 122 eyes had extracapsular cataract extraction (ECCE). Postoperative visual acuity and intraocular pressure (IOP) were analyzed on the first postoperative day, 3 months after surgery, and 6 months after surgery.

Results: Best corrected visual acuity (BCVA) improved in 100 of 122 eyes (82.0\%). BCVA remained the same in 20 of 122 eyes (16.4\%) and decreased in 2 of 122 eyes (1.6\%), mainly because of coexisting age-related macular degeneration (AMD). The BCVA 3 months after surgery was $\geq 0.8$ in 23 of 122 eyes (18.9\%), between 0.5 and 0.7 in 28 of 122 eyes $(22.3 \%)$, and between 0.2 and 0.4 in 33 of 122 eyes (27.1\%). We found significant implications of cataract surgery on decreasing IOP in the studied group of patients suffering from glaucoma compared to the patients without glaucoma.

Conclusion: Advanced age is not a contraindication for cataract surgery. The results of the study showed that when systemic conditions are stable, both phaco and ECCE with IOL for very elderly patients are effective and safe.

Keywords: very elderly patients, cataract surgery, postoperative best corrected visual acuity, intraocular pressure

\section{Introduction}

Age-related ocular diseases such as cataracts will assume increasing importance in the public health of the Polish nation. Cataracts are a common cause of visual acuity (VA) loss and reduced quality of life in the elderly population. ${ }^{1}$

Over the last few years, life expectancy in Poland has been increasing steadily, and forecasts for the future are optimistic. For men, this rate is predicted to grow from the current 70.4 years to 77.6 years by 2035 , while for women, we can expect an increase from 78.8 years to 83.3 years (compared with 56.0 and 61.6 years, respectively, in 1950). ${ }^{2}$

The occurrence of cataracts is strongly related to aging; however, there is little information in the literature on the final visual results and safety of cataract surgery and intraocular lens (IOL) implantation in the group defined as "very elderly." 3,4

In a study of 802 consecutive cataract operations, Berler found that patients $>88$ years of age were at increased risk of complications compared with those under $88 .{ }^{5}$ Syam et al also found a higher incidence of complications, in a retrospective study of 
perioperative complications of cataract surgery in a group of very elderly patients, although the studied group was small (34 eyes from 21 patients). ${ }^{6}$

The number of patients eligible for cataract surgery is predicted to increase as a result of greater surgical safety and an increase in the proportion of elderly people in the population. ${ }^{7}$ Furthermore, visual impairment leads to reduced quality of life, poorer general health, and increased mortality. ${ }^{8,9}$

Cataracts are one of the conditions responsible for impaired vision in the very elderly. The decrease of vision is a serious risk factor for loss of balance, perhaps leading to falls and injury. Many risk factors for falling among elderly people have been identified in epidemiological studies, including poor vision. ${ }^{10}$ Hip fractures in the elderly are commonly caused by falls. The authors established that cataract surgery is an effective intervention to reduce the risk of falls in elderly patients with cataract-related visual impairment. ${ }^{11-13}$

The aim of our study was to retrospectively evaluate the effectiveness and safety of cataract surgery and IOL implantation in patients aged 90 years or older, whom we define as "very elderly." Visual outcomes and their relation to the coexisting disorders and to the complications were analyzed.

\section{Methods}

The study was retrospectively conducted between 2008 and 2010 at University Hospital No 5 of the Medical University of Silesia. The study involved a total of 122 patients (122 eyes) with senile cataracts. All operations were performed by surgeons from the Special Cataract Clinic, who are all highly experienced in phacoemulsification (phaco).

In this study we included patients $>90$ years old, who had significant bilateral cataracts causing impairment of visual functions not correctable by glasses (best corrected visual acuity [BCVA] worse than 0.7 ), or with unacceptable glare, polyopia, or reduced quality of vision attributable to cataracts. The exclusion criteria were age under 90 years, a preoperative BCVA of 0.7 or better, a baseline endothelial cell density of less than 1500 cells $/ \mathrm{mm}^{2}$, uncontrolled glaucoma, and physical or mental disability that would make it difficult to perform the surgery. The mean age of the patients was $91.2 \pm 2.3$ years (range 90-100 years old). Surgery was performed on 43 men (mean age 90.4 years) and 79 women (mean age 91.5 years). Phaco was done on 113 of 122 eyes and 9 of 122 eyes had extracapsular cataract extraction (ECCE).

\section{Surgical techniques}

Phaco was developed in 1967 by Charles D Kelman and is now the most common technique used in developed countries. ${ }^{14}$
It involves the use of ultrasounds to emulsify the cataractous lens through a small incision (1.8-3.2 mm). The artificial IOL is inserted directly to the lens capsule.

ECCE involves the removal of the cataractous lens while the posterior capsule is left intact to allow implantation of an intraocular lens. The lens is removed through a large (usually 10-12 mm) incision. This method may be indicated for patients with very hard cataracts.

The type of anesthesia used depended on the preference of the surgeon and general condition of the patient. These included topical drop anesthesia in 110 of 122 patients, subTenon's and peribulbar anesthesia in 10 of 122 patients, and general anesthesia only in two cases because of inability to understand verbal commands.

During the clinical examination on the day of surgery, visual and clinical data were collected prospectively. Ocular comorbidity was defined as: coexisting ocular disease identified preoperatively that was likely to limit the final VA outcome. The Snellen VA was converted to decimal values for statistical calculations.

The primary outcome measures were postoperative BCVA, intraocular pressure (IOP) using Goldmann Applanation Tonometry, and intraoperative and postoperative complications. Postoperative VA and IOP were analyzed on the first postoperative day, 3 months, and 6 months after surgery.

The statistical analysis was carried out using the Statistica 10.0 PL (StatSoft, Inc., Tulsa, OK, USA) with Student's $t$-test performed for normal distribution (preoperative IOP between patients with and without coexisting glaucoma, pre- and postoperative IOP in both groups) of the results in the study groups, or the Mann-Whitney $U$ test in non-normal distribution (postoperative IOP between patients with and without coexisting glaucoma). Analysis of variance (ANOVA) with Tukey's HSD post-hoc test was applied to compare the first day, 3 months, and 6 months after surgery. For all statistical tests, a $P$-value of $<0.05$ was considered to indicate statistical significance.

All subjects gave an informed consent before participating in the study, and research followed the tenets of the Declaration of Helsinki.

\section{Results}

In the group of 122 eyes, 41 (33.6\%) had no ocular comorbidity identified before surgery. The 81 eyes $(66.4 \%)$ with ocular comorbidity included $54(44.3 \%)$ with age-related macular degeneration, 26 (21.3\%) with glaucoma, 15 (12.3\%) with pseudoexfoliation syndrome, $8(6.6 \%)$ with corneal opacity, $15(12.3 \%)$ with hypertensive retinopathy, and $9(7.4 \%)$ with diabetic retinopathy. 
Mean postoperative scores were significantly better compared to the preoperative level. The BCVA was $\leq 0.1$ in 94 of 122 eyes (77.1\%), between $0.2-0.4$ in 24 of 122 eyes (19.7\%), and between $0.5-0.7$ in four of 122 eyes (3.3\%). The postoperative BCVA 3 months after surgery was $\geq 0.8$ in 23 of 122 eyes (18.9\%), between $0.5-0.7$ in 28 of 122 eyes (22.3\%), and between $0.2-0.4$ in 33 of 122 eyes $(27.1 \%)$.

VA improved in 100 of 122 eyes (82.0\%), remained the same in 20 of 122 eyes (16.4\%), and decreased in two of 122 eyes (1.6\%), mainly because of coexisting age-related macular degeneration (AMD).

We found significant difference between pre- and postoperative VA on the first day, 3 months, and 6 months after cataract surgery. We also found significant difference between VA measured on the first day and 3 months after surgery, but there was no difference between the 3-month and 6-month postoperative VA. We did not observe significant differences in VA between patients operated on with phaco and ECCE between 3 months and 6 months after surgery. The results are presented in Table 1 and Figure 1.

We found significant difference in preoperative IOP between patients with and without coexisting glaucoma $(17.7 \pm 3.4 \mathrm{mmHg}$ versus $14.8 \pm 2.4 \mathrm{mmHg}, P=0.002)$.

On the first postoperative day we observed a decrease of IOP in the group of glaucoma patients $(14.2 \pm 2.4 \mathrm{mmHg})$, but there was no difference in IOP compared to patients without glaucoma (14.5 $\pm 2.5 \mathrm{mmHg})$. Postoperative IOP had significantly decreased in glaucoma patients compared to the preoperative period $(17.7 \pm 3.4 \mathrm{mmHg}$ versus $14.2 \pm 2.4 \mathrm{mmHg}, P=0.002$ ). We found no difference in IOP on the first day, 3 months, and 6 months after surgery. Results are presented in Figure 2.

Table I Details of follow-up and visual outcomes in very elderly patients following cataract surgery

\begin{tabular}{|c|c|c|c|c|c|}
\hline & Mean & SD & Median & Minimum & Maximum \\
\hline Age (years) & 91.20 & 2.30 & 90.00 & 90.00 & 100.00 \\
\hline $\begin{array}{l}\text { IOL power } \\
\text { (diopter) }\end{array}$ & 22.70 & 2.80 & 22.50 & 16.00 & 35.00 \\
\hline $\begin{array}{l}\text { BCVA - before } \\
\text { surgery }\end{array}$ & 0.09 & 0.13 & 0.04 & 0.01 & 0.70 \\
\hline $\begin{array}{l}\text { BCVA - day I } \\
\text { after surgery }\end{array}$ & 0.31 & 0.29 & 0.20 & 0.01 & 1.00 \\
\hline $\begin{array}{l}\text { BCVA - } 3 \text { months } \\
\text { after surgery }\end{array}$ & 0.39 & 0.29 & 0.40 & 0.01 & 1.00 \\
\hline $\begin{array}{l}\text { BCVA - } 6 \text { months } \\
\text { after surgery }\end{array}$ & 0.36 & 0.25 & 0.30 & 0.01 & 0.90 \\
\hline
\end{tabular}

Abbreviations: BCVA, best corrected visual acuity; IOL, intraocular lens; $\mathrm{SD}$, standard deviation.
The most frequent complications following cataract surgery in very elderly patients in our study were posterior capsule tear without vitreous loss and corneal decompensation. Both were found in three patients $(2.5 \%)$. A dropped nucleus and vitreous loss were found in only one eye $(0.8 \%)$. Postoperative uveitis occurred in two eyes ( $1.6 \%)$. The overall complications rate in the studied group of very elderly patients was $8.2 \%$.

\section{Discussion}

Cataracts are one of the most frequent reasons for visual impairment around the world. Cataracts in very elderly patients can cause progressively painless vision loss. Because of the demographic shift in developed countries toward older age, the prevalence of cataracts in the population as a whole has increased. It is difficult to perform cataract surgery on an elderly patient owing to additional difficulties like coexisting systemic disorders, the difficulty of patient cooperation during surgery, higher incidence of hard nucleus, smaller pupil size and high rate of pseudoexfoliation syndrome. We found little evidence to support the hypothesis that age alone is a risk factor for the intraoperative complications of phaco cataract surgery.

The lack of data on very elderly patients may be due to the relatively few patients of this age who have undergone cataract surgery. Guzek et al had only 84 patients $>80$ years of age in a group of 1000 cases of cataract surgery; ${ }^{15}$ Davison conducted a study of 2839 patients wherein only $1.3 \%$ of the patients were aged $\geq 90$ years. ${ }^{16}$

Many elderly people have ocular and systemic comorbidities. In a UK National Cataract Surgery Survey, one in three participants had a pre-existing ocular condition that could significantly affect cataract surgery outcomes. ${ }^{17}$ In that study, AMD was present in $15 \%$ of the participants, glaucoma in $10 \%$, and diabetic retinopathy in $3 \%$. The prevalence of these conditions, as expected, increased with age.

In the Medical Research Council Assessment and management of older people in the community trial, the authors found that in both men and women aged $\geq 90$ years, AMD is the most important cause of visual loss (55.6\% and 53.7\%), and cataracts were the cause of visual loss in $33.3 \%$ and $24.1 \%$, respectively. ${ }^{1}$

Berler found that in patients under 88 years, $90.5 \%$ of eyes with complicated cataract surgery achieved a VA $>6 / 12$, compared with only $40 \%$ of complicated cataract cases when patients were $>88$ years old. ${ }^{5}$ In a previous study, Westcott et al found that age is a significant determinant of visual outcome, with the odds of a patient with no comorbidity 


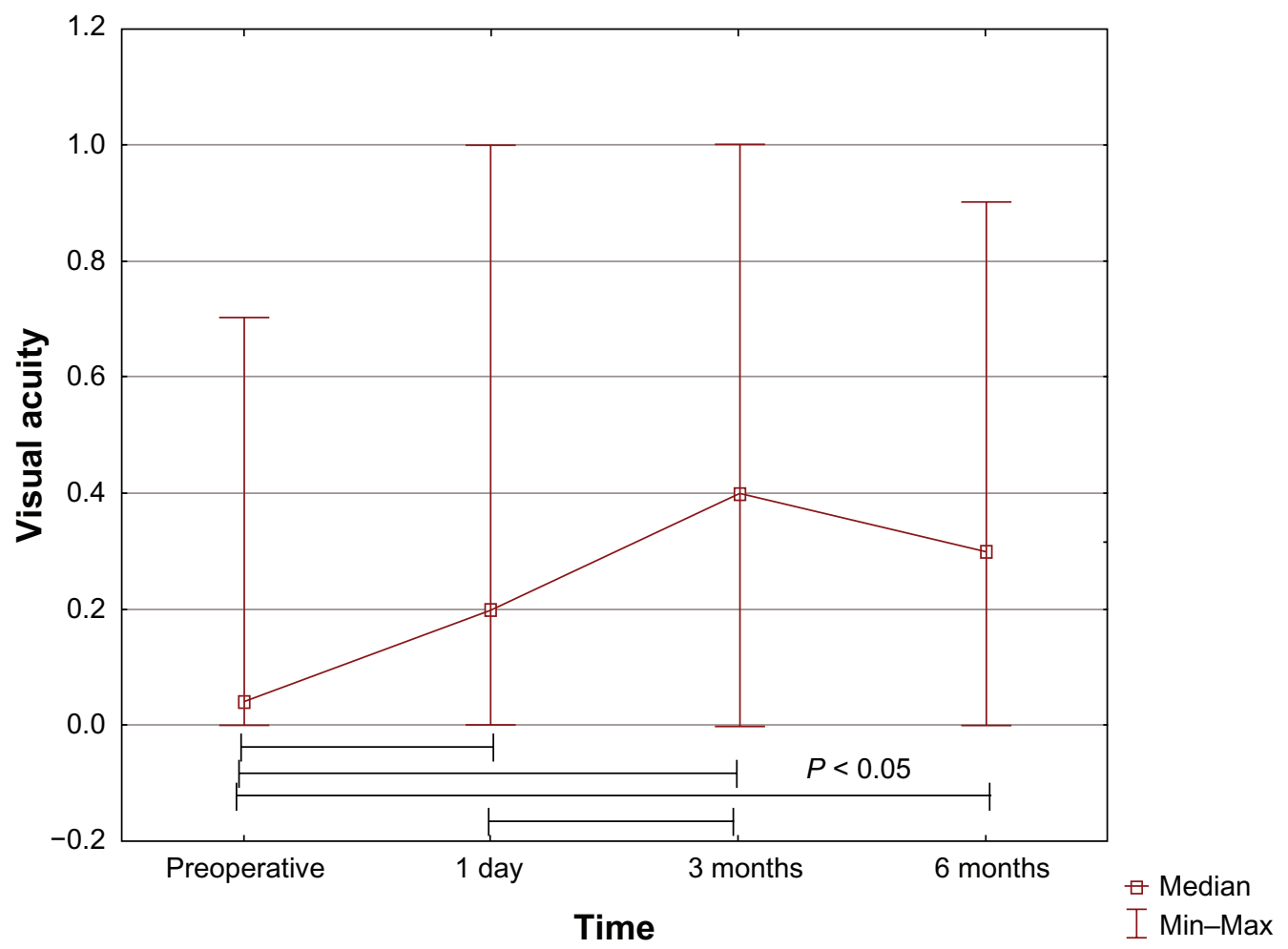

Figure I Visual acuity in the studied group $(n=122)$ of very elderly patients before and after cataract surgery (ANOVA). Abbreviations: ANOVA, analysis of variance; Min-Max, minimum to maximum.

achieving acuity VA of $>6 / 12$ being 4.6 times higher in the 60-69 year old age group than in those $>80$ years old. ${ }^{18}$

Our study supports these observations and others. Lundström et al have shown improvement in VA in $84.3 \%$ of patients $>85$ years. ${ }^{19}$ Similarly, a study carried out by Applegate et al has shown improved VA in a majority of the patients $(88 \%)$ above 70 years old following cataract surgery. ${ }^{20}$ Our study showed that postoperative VA improved in $84 \%$ of cases. VA remained the same in $16.4 \%$ and deteriorated in $1.6 \%$ of the cases; this deterioration was attributed in $62.2 \%$ of the cases to the underlying advanced AMD.

The incidence of early postoperative IOP increase is reported to be $2.3 \%-8.9 \%$ in all cataract extractions. ${ }^{21}$ In another study, Kim et al found more frequent $(22.0 \%)$ increased IOP on the first postoperative day following cataract surgery. ${ }^{22}$ The extent of such an early IOP increase was reported to be related to anterior chamber inflammation and prostaglandin release, capsulorhexis size, or residual viscoelastic material in the anterior chamber. ${ }^{23}$ In contrast to the results of that study, in our study's group of elderly patients we did not find that cataract surgery resulted in an increase of the IOP on the first postoperative day, 3 months, and 6 months after surgery; we also found significant decrease of the IOP in patients with preoperatively existing glaucoma.
It is not surprising that AMD was the primary cause of visual impairment in the studied group of patients after cataract surgery - that is consistent with results presented by other authors. ${ }^{5}$ In the newest study, Owen et al report the prevalence of late AMD standardized to the UK population aged 50 years or older was $2.4 \%$, increasing to $4.8 \%$ in those aged 65 years or older, and $12.2 \%$ in those aged 80 years or older. ${ }^{24}$

In another study, Jonasson et al found a higher prevalence of AMD in the studied group..$^{25}$ The prevalence of early AMD was $12.4 \%$ for those aged $66-74$ years and $36 \%$ for those aged $\geq 85$ years. This is consistent with the results of our study. The authors concluded that persons aged $\geq 85$ years have a 10-fold higher prevalence of late AMD than those aged 70-74 years. ${ }^{25}$ Surgery is an effective treatment for agerelated cataract-induced visual loss, though some clinicians suspect that such an intervention may increase the risk of worsening underlying AMD, and thus may have deleterious effects on vision.

Casparis et al found no significant difference in the development of AMD between groups in the immediate cataract surgery group versus patients in the delayed surgery group. ${ }^{26}$ The authors suggested that the immediate surgery group fared better with quality of life outcomes than the delayed surgery group; ${ }^{26}$ however, even in patients with AMD, 

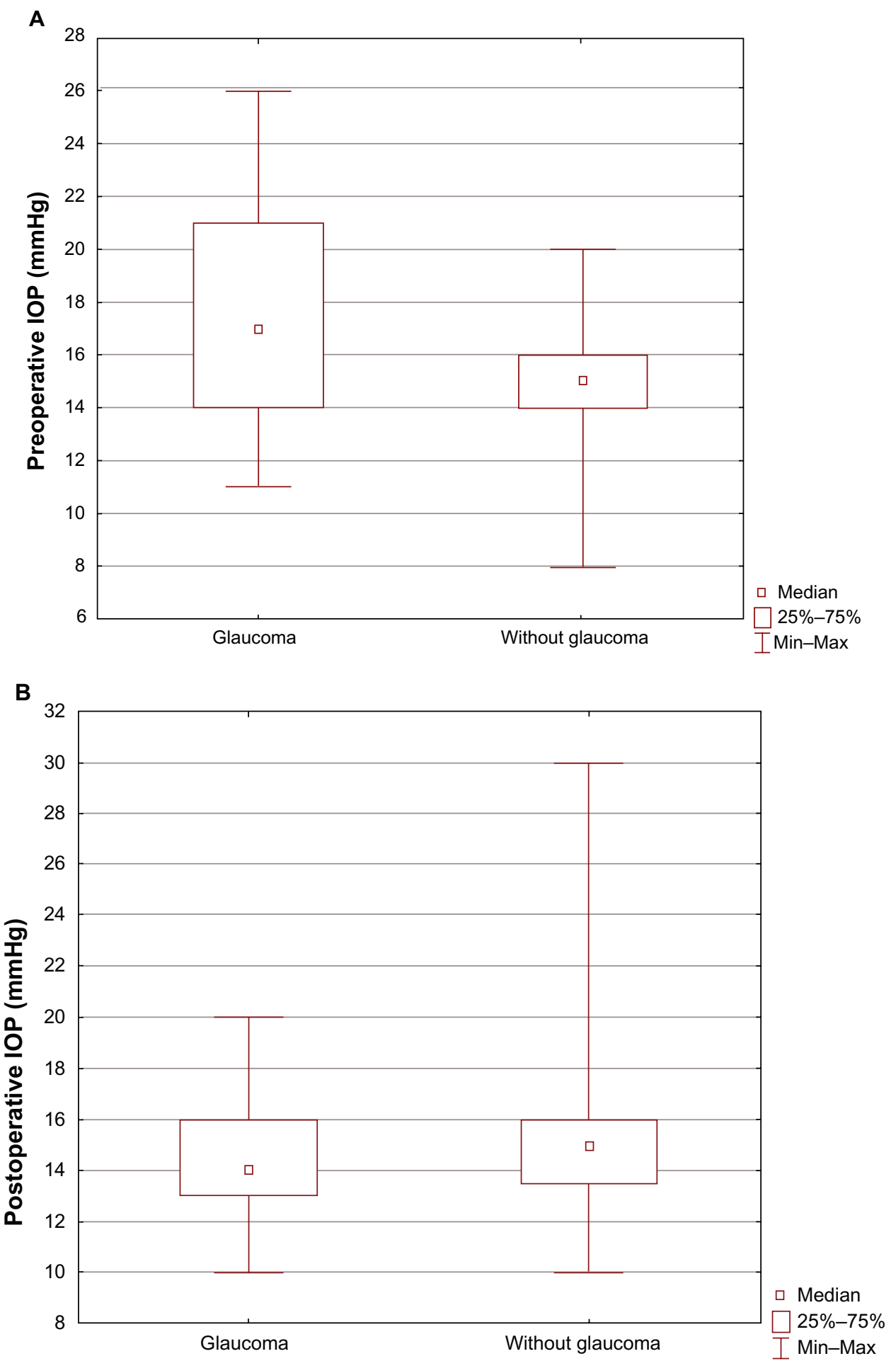

Figure 2 IOP in patients before (A) and after (B) cataract surgery.

Notes: IOP in glaucoma patients $(n=26)$ and patients without glaucoma $(n=96)$ before (Student's t-test) and after cataract surgery $($ Mann-Whitney $U$ test)

Abbreviations: IOP, intraocular pressure; Min-Max, minimum to maximum.

where central vision is lost, the peripheral visual field necessary for confident navigation can be improved by cataract surgery, and can improve quality of life for very elderly patients. In a series of studies, it was found that reduced contrast sensitivity and visual field size, rather than VA, were more strongly associated with falls and fractures in elderly people. ${ }^{27,28}$ Although $27.7 \%$ of the AMD patients have not obtained a significant improvement of BCVA, in contrast to some previous studies we also have not observed a deterioration of VA in an observation period of 6 months..$^{29,30}$ 


\section{Conclusion}

The results of the study showed that when systemic conditions are stable both phaco and ECCE with IOL implantation for very elderly patients are effective and safe. Advanced age is not a contraindication for cataract surgery. Restoration of visual function, especially in people with severe VA reduction, has a positive impact on the psychological state of patients.

\section{Disclosure}

The authors have no financial or proprietary interest in any of the products or techniques mentioned in this presentation. This work was not supported by any organization.

\section{References}

1. Evans JR, Fletcher AE, Wormald RP; MRC Trial of Assessment and Management of Older People in the Community. Causes of visual impairment in people aged 75 years and older in Britain: an add-on study to the MRC Trial of Assessment and Management of Older People in the Community. Br J Ophthalmol. 2004;88(3):365-370.

2. Glowny Urzad Statystyczny [webpage on the Internet]. Life expectancy tables of Poland. Central Statistical Office; 2011. Available from: http:// www.stat.gov.pl/cps/rde/xbcr/gus/POP_life_expectancy_in_2011.pdf. Accessed July 10, 2013.

3. Leske MC, Sperduto RD. The epidemiology of senile cataracts: a review. Am J Epidemiol. 1983;118(2):152-165.

4. Robbie SJ, Muhtaseb M, Qureshi K, Bunce C, Xing W, Ionides A. Intraoperative complications of cataract surgery in the very old. $\mathrm{Br} \mathrm{J}$ Ophthalmol. 2006;90(12):1516-1518.

5. Berler DK. Intraoperative complications during cataract surgery in the very old. Trans Am Ophthalmol Soc. 2000;98:127-130.

6. Syam PP, Eleftheriadis H, Casswell AG, Brittain GP, McLeod BK, Liu CS. Clinical outcome following cataract surgery in very elderly patients. Eye (Lond). 2004;18(1):59-62.

7. Minassian DC, Reidy A, Desai P, Farrow S, Vafidis G, Minassian A. The deficit in cataract surgery in England and Wales and the escalating problem of visual impairment: epidemiological modelling of the population dynamics of cataract. Br J Ophthalmol. 2000;84(1):4-8.

8. Finger RP, Kupitz DG, Holz FG, et al. The impact of the severity of vision loss on vision-related quality of life in India: an evaluation of the IND-VFQ-33. Invest Ophthalmol Vis Sci. 2011;52(9):6081-6088.

9. Lamoureux EL, Fenwick E, Pesudovos K, Tan D. The impact of cataract surgery on quality of life. Curr Opin Ophthalmol. 2011;22(1):19-27.

10. Harwood RH. Visual problems and falls. Age Ageing. 2001;30 (Suppl 4): 13-18.

11. Brannan S, Dewar C, Sen J, Clarke D, Marshall T, Murray PI. A prospective study of the rate of falls before and after cataract surgery. Br J Ophthalmol. 2003;87(5):560-562.

12. Foss AJ, Harwood RH, Osborn F, Gregson RM, Zarnan A, Masud T. Falls and health status in elderly women following second eye cataract surgery: a randomised controlled trial. Age Ageing. 2006;35(1): 66-71.

Clinical Interventions in Aging

\section{Publish your work in this journal}

Clinical Interventions in Aging is an international, peer-reviewed journal focusing on evidence-based reports on the value or lack thereof of treatments intended to prevent or delay the onset of maladaptive correlates of aging in human beings. This journal is indexed on PubMed Central, MedLine, the American Chemical Society's 'Chemical Abstracts
13. Kulmala J, Viljanen A, Sipilä S, et al. Poor vision accompanied with other sensory impairments as a predictor of falls in older women. Age Ageing. 2009;38(2):162-167.

14. Kelman CD. Phaco-emulsification and aspiration. A new technique of cataract removal. A preliminary report. Am J Ophthalmol. 1967;64:23-35.

15. Guzek JP, Holm M, Cotter JB, et al. Risk factors for intraoperative complications in 1000 extracapsular cataract cases. Ophthalmol. 1987;94(5):461-466.

16. Davison JA. Acute intraoperative suprachoroidal hemorrhage in extracapsular surgery. J Cataract Refract Surg. 1986;12(6): 606-622.

17. Gray CS, Crabtree HL, O'Connell JE, Allen ED. Waiting in the dark: cataract surgery in older people. BMJ. 1999;318(7195):1367-1368.

18. Westcott MC, Tuft SJ, Minassian DC. Effect of age on visual outcome following cataract extraction. Br J Ophthalmol. 2000;84(12): $1380-1382$.

19. Lundström M, Stenevi U, Thorburn W. Cataract surgery in the very elderly. J Cataract Refract Surg. 2000;26(3):408-414.

20. Applegate WB, Miller ST, Elam JT, Freeman JM, Wood TO, Gettlefinger TC. Impact of cataract surgery with lens implantation on vision and physical function in elderly patients. JAMA. 1987;257(8): 1064-1066.

21. McKellar MJ, Elder MJ. The early complications of cataract surgery: is routine review of patients 1 week after cataract extraction necessary? Ophthalmology. 2001;108(5):930-935.

22. Kim JY, Jo MW, Brauner SC, et al. Increased intraocular pressure on the first postoperative day following resident performed cataract surgery. Eye (Lond). 2011;25(7):929-936.

23. O'Brien PD, Ho SL, Fitzpatrick P, Power W. Risk factors for a postoperative intraocular pressure spike after phacoemulsification. Can J Ophthalmol. 2007;42(1):51-55.

24. Owen CG, Jarrar Z, Wormald R, Cook DG, Fletcher AE, Rudnicka AR. The estimated prevalence and incidence of late stage age related macular degeneration in the UK. Br J Ophthalmol. 2012;96(5):752-756.

25. Jonasson F, Arnarsson A, Eriksdottir G, et al. Prevalence of agerelated macular degeneration in old persons: Age, Gene/environment Susceptibility Reykjavik Study. Ophthalmology. 2011;118(5):825-830.

26. Casparis H, Lindsley K, Kuo IC, Sikder S, Bressler NB. Surgery for cataracts in people with age-related macular degeneration. Cochrane Database Syst Rev. 2012;6:CD006757.

27. de Boer MR, Pluijm SM, Lips P, et al. Different aspects of visual impairment as risk factors for falls and fractures in older men and women. J Bone Miner Res. 2004;19(9):1539-1547.

28. Lord SR. Visual risk factors for falls in older people. Age Ageing. 2006;35 Suppl 2:ii42-ii45.

29. Fraser-Bell S, Choudhury F, Klein R, Azen S, Varma R; Los Angeles Latino Eye Study Group. Ocular risk factors for age-related macular degeneration: the Los Angeles Latino Eye Study. Am J Ophthalmol. 2010;149(5):735-740.

30. Ho L, Boekhoorn SS, Liana, et al. Cataract surgery and the risk of aging macula disorder: the Rotterdam study. Invest Ophthalmol Vis Sci. 2008;49(11):4795-4800.

Service' (CAS), Scopus and the Elsevier Bibliographic databases. The manuscript management system is completely online and includes a very quick and fair peer-review system, which is all easy to use. Visit http://www.dovepress.com/testimonials.php to read real quotes from published authors. 